\title{
Differenz
}

Revista internacional de estudios heideggerianos y sus derivas contemporáneas

AÑO 3 NÚMERO 2: JULIO DE 2016. e-ISSN: 2386-4877 - DOI: 10.12795/DIFFERENZ.2016.I02.15

[pp. 255-262]

\section{Slavoj Žizek: sobre el goce en la moral y en la política.}

\section{Slavoj Žizek: on the enjoyment in morality and politics.}

\author{
Luís Roca Jusmet ${ }^{1}$ \\ Catedrático Filosofía ES. Barcelona
}

\section{Introducción ${ }^{2}$}

A partir de la lectura crítica de artículo ("El malestar de la democracia formal") de la tercera parte ("Fantasía, burocracia, democracia") del libro de Slavoj Žižek Mirando al sesgo.

1 Catedrático de filosofía de secundaria en Barcelona. Colaborador de la revista El Viejo Topo y el sitio web Rebelión. Colaborador y miembro del consejo científico de la revista PAIDEIA. Ha publicado el libro Redes y obstáculos. Ed.Club Universitario, 2010. Colaboraciones en otros libros: "Complementos disciplinarios" en Didáctica de la Filosofía, Graó, 2009; "Crítica del multiculturalisme" en Globalització i interculturalitat, Barcelona: La Busca, 2010; "L’actualitat de Schopenhauer", en Schopenhauer avui, Barcelona: La Busca, 2011; "Una mirada filosòfica a la narrativa cinematogràfica de David Lynch", en Art i filosofia, Barcelona: La Busca, 2011; "Claude Lefort : Repensar la política" y "François Jullien : una mirada filosófica a China", en Filosofías postmetafísicas, 20 años de filosofía francesa contemporánea, Barcelona, UOC, 2012; "El diáleg (imposible) entre Pierre Hadot i Michel Foucault", en La Filosofia com forma de vida, Barcelona: La Busca, 2013; "Teories democràtiques radicales : Jacques Rancière i Cornelius Castoriadis", en Hi ha una nova politica?, Barcelona: La Busca, 2014.

2 Conferencia pronunciada en la Universidad de Sevilla el 20 de Mayo de 2016 dentro del marco del IV Coloquio SPF: Sujeto, Psicoanálisis y Filosofía organizado por el Grupo de Investigación Filosofía Aplicada: Sujeto, Sufrimiento, Sociedad (HUM 018) 
Jacques Lacan a partir de la cultura popular, quiero plantear una serie de problemáticas relacionados con la ética, la moral y la política contemporáneas.

En primer lugar voy a explicar lo que entiendo por cada una de los tres conceptos. Mantengo la diferencia conceptual entre ética y moral, aunque para algunos se confunden los dos términos o se considera que el primero es lo que estudia el segunda. Me parece que hay que entender la ética como un arte de vivir, como la práctica singular de la libertad. La moral es lo que nos hace salir de nosotros y nos obliga respecto a los otros. Implica, por tanto, un altruismo, un salir de uno mismo. La política es el tercer aspecto que nos lleva a construir lo público con los otros.

Para seguir el planteamiento de Žižek vamos a explicar los conceptos básicos, estrictamente lacanianos, Empezamos por la noción de pulsión. Es el más allá del principio del placer (búsqueda homoestática de la satisfacción) y de realidad (adaptarse a las circunstancias, a las exigencia) que sería el interés. Es el exceso vital, tanto la sexual como la de muerte (paradigma de pulsión). La pulsión de muerte no tiende al nirvana, al cero, tiende al goce (que es un placer límite ligado a la tensión y, por tanto, al dolor). Es la negatividad de Schelling-Hegel, lo que hace autónomo al ser humano y le lleva más allá de lo adaptativo y del cálculo utilitarista. Podemos entenderla a partir del juicio infinito de Kant, que no es juicio afirmativo ni juicio negativo. Es, por tanto, la no-vida. La pulsión es resultado de la energía de un instinto descabezado, privado de su objeto natural. Los humanos somos una anomalía, pero no a causa de la socialización y la cultura, ya que estas son las que se ponen en marcha para establecer un nuevo vínculo. Porque el ser humano es extraño a su entorno, está separado de él por su autoconciencia. Es, como decía el Hegel juvenil, la "noche del mundo". Este ser pulsional se inscribe en el orden simbólico. Se inscribe a través del significante, que será el mediador entre el hombre y el mundo. La palabra es el asesinato de la cosa, pero esta cosa ya estaba perdida, existe solo retroactivamente. Pero para constituir esta identidad simbólica hemos de tomar un punto constitutivo, un lugar, una posición que nos constituya como sujetos. Este es el significante-amo, el sujeto a partir del cual constituimos nuestra cadena significante. el sujeto de la enunciación, el sujeto desde el que hablamos. Es el Yo ideal, que adquirimos a partir de la metáfora paterna. Esta la establecemos a partir del significante reprimido, el significante fálico, que es el de la falta. Hablamos de nuestro yo, sujeto del enunciado, que es una identidad imaginaria. La pulsión, en la medida que se identifica con este yo produce un goce narcisista, el del yo ideal. Pero desde el significante-amo se constituye también el superyó, con la energía de la pulsión y que como tal produce un gozo. El Yo ideal es la ley, vacía en sí misma, constituyente. El superyó es la parte oscura, irracional, de esta ley constituida a través de normas abstractas. Lo que sacrifica el superyó es el 
deseo y por esto nos sentimos culpables. No es que nos sintamos culpables por no seguir el superyó sino por seguirlos, lo cual explica que contra más rígidos somos más culpables nos sentimos.

¿Qué es este deseo que sacrificamos? Es lo que surge de lo que Lacan llama el objeto "a", que es el resto que queda la pulsión transformada en demanda de amor. Cuando esto ocurre podemos ligar la pulsión a un significante y por tanto regularla. Quiero decir que entonces queremos algo, algo que nunca cubre nuestra demanda y por tanto el deseo se mantiene. Pero se acepta la castración simbólica que nos permite esta falta desde la que desear y el deseo es, en este sentido, una defensa contra la pulsión no regulada, mortífera, que nos lleva a la destrucción. Cuando podemos transformar el vacío, el agujero en torno al cual gira la pulsión circularmente, en falta, entonces hay deseo y goce regulado.

Desde estos conceptos lacanianos Žižek quiere elaborar una propuesta ética. Pero también una propuesta política enlazando la ética lacaniana con la política de Marx y Lenin. Para ello planteará una crítica al liberalismo en sus dimensiones ética, moral y política. Igualmente se ocupará de otro fenómeno moderno, que es el totalitarismo.

\section{La propuesta ético-moral liberal}

La realidad tiene forma de ficción, porque está organizada simbólicamente, pero es siempre de manera incompleta, con fallo. Lo que queda sin simbolizar aparece como un espectro. La ideología es una especie de fantasía social, una respuesta al agujero de lo real. No podemos considerar que la ideología sea una falsa representación detrás de la cual se esconde la realidad porque esta solo existe construida por la ideología. Justamente ver la ideología es ver lo que hay detrás de nuestros actos cotidianos, lo que detrás de pedir una hipotética, de hacer un viaje o comprar un noche. Como dice Marx en El capital: no saben lo que hacen, pero lo hacen igual. La ideología propia del capitalismo es el liberalismo.

Žižek analiza la propuesta liberal a partir de uno de sus representantes más sugerentes, Richard Rorty, un postmoderno seguidor del moderno Mill. Žižek problematiza este planteamiento desde otra tradición, que es la psicoanalítica. Freud plantea que hay un más allá del principio del placer y este más allá, para el filósofo esloveno es la pulsión, sobre todo la pulsión de muerte, y el goce. La pulsión viene a ser el instinto descabezado, desarraigado que nos hace circular en torno a un goce que es un exceso, una tensión que limita con el dolor. Filosóficamente lo identifica con la negatividad de Schelling y Hegel. ¿Donde está el goce en las propuestas liberales de Rorty? En su ética de la autocreación no contempla ni la pulsión ni la roca del inconsciente. 
La diferencia entre lo privado, en la que debe existir una libertad perfecta, y lo publico, donde las normas limitan el espacio del otro, se concretan en Rorty en la autocreación y la solidaridad, que no es otra cosa que el respeto a la singularidad del otro. Todo esto está muy bien, dice Žižek, si no hubieran dos problemas. El primero es que en el problema de la autocreación no tenemos en cuenta la roca del inconsciente. Es decir, que podemos narrarnos nuestra vida como queramos, pero esto opera en el registro imaginario, el de las identificaciones y, por lo tanto, las sugestiones. Lo real de cada cual se manifiesta en el síntoma y hemos de atravesar la fantasía que nos atrapa para enfrentarnos a nuestro síntoma y saber que hacer con él. Lo que quiere decir que deje de ser motivo de sufrimiento para pasar a ser motivo de goce, nuestro modo singular de gozar. Hablamos entonces de un goce regulado a través del sinthome, concepto lacaniano tardío que viene a ser una especie de significante donde se encuentran el síntoma y la fantasía. Es operando sobre lo real y no sobre el imaginario cuando hay transformación real. Tampoco esta autocreación parece incidir en el terreno de lo simbólico. Lo simbólico está marcado por el significante amo y este es el núcleo de nuestro carácter, de nuestra posición respecto a nosotros mismos y los otros.

Pero el autentico problema es para Žižek las consecuencias morales del liberalismo. Porque para Rorty la ética de la solidaridad con el otro, que es lo que defiende Rorty, es la que nos permite convivir en un mundo donde cada cual puede realizar su fantasía. Pero este límite, para Žižek es un imperativo del superyó y el superyó siempre es obsceno, siempre retiene un goce. Esto quiere decir que detrás de la solidaridad debe haber un goce, una obscenidad. No es posible que la moral pública sea neutra porque es patológico, esta impregnada de goce y esto es lo que lo hace peligroso, torcido, pero al mismo tiempo es lo que nos obliga con el otro.

En todo caso si volvemos a Mill, y aquí entra mi reflexión personal, vemos como este también plantea que el deseo de virtud tiene que se un deseo altruista que funciona en la medida en que la educación potencia los sentimientos de empatía y nos hacer querer el bien del otro como nuestro propio bien. Claro que Mill no contemplaba "los dioses oscuros" de los que habla Žižek, siguiendo a Freud y a Lacan. De todas maneras, en mi opinión, la crítica de Zizek es una reserva más que una impugnación del planteamiento de Rorty. Con esto quiero decir que en el primer aspecto Rorty entra en el planteamiento no solo de Mill sino también del último Foucault de que la ética es la construcción de la propia subjetividad.

¿Cómo podemos reconocer al otro sin pasar por la construcción de un superyó rígido? ¿Cómo construir una moral sin una ley que sacrifique el deseo? 


\section{La propuesta política del liberalismo}

Finalmente tenemos la democracia liberal como la propuesta política del liberalismo. Pero esto también plantea críticas muy serias. En primer lugar tenemos en la democracia un sujeto vacío, un sujeto de derechos sin atributos, universal. Para Žižek, siguiendo a Lacan, el síntoma de la democracia liberal es el racismo cultural. El síntoma quiere decir, como sabemos, la manifestación de lo reprimido. Žižek desarrolla el tema desde la patología del nacionalismo y la extrema derecha populista como las dos vertientes de este racismo cultural.

El nacionalismo es donde se desplaza el goce en la democracia liberal, ya que es la identificación narcisista, la de las pequeñas diferencia que nos decía Freud, que nos permite un goce. Porque el sujeto vacío de la democracia liberal no permite ningún tipo de identificación ni de goce. Pero la nación si lo hace, porque es la Cosa que dignificamos como objeto de la pulsión. De esta manera, e históricamente se puede comprobar, el liberalismo se ha desarrollado de la mano de su contrario, el todo lleno del nacionalismo.

Pero también podemos comprobar que el liberalismo multicultural de la tolerancia lo que hace es reprimir este rechazo al Otro. Este Otro es rechazado porque rechazamos, en definitiva, este goce del Otro. Lo que socialmente tolera el discursos políticamente correcto del liberalismo aparece en la parte reprimida de este superyó que no tolera al Otro. Esto hace que cuando aparece el discursos liberal como dominante siempre se acompaña con la aparición de la xenofobia. Lo paradójico es que todas las medidas restrictivas que propone el populismo de extrema derecha acaban siendo asimiladas por las políticas liberales.

Es decir que el liberalismo es un discurso que se acompaña siempre por el goce del nacionalismo y por el rechazo al goce del Otro que es el racismo cultural. La trampa del liberalismo es hacernos creer que el nacionalismo y el populismo extremista son su contrario, cuando en realidad son sus síntomas, es decir sus consecuencias.

\section{La aparición del totalitarismo}

Slavoj Žižek parte de la consideración de Claude Lefort de que el fin de la sociedad tradicional conduce a una indeterminación que solo puede dar lugar a la democracia, en la que el lugar del poder está vacío y puede ser ocupado por cualquiera totalitarismo en el que, 
como decía Freud en su Psicología de masas el líder ocupa el lugar del Ideal. La autoridad tradicional se basa en la mística de la institución. Es un poder performativo, un poder fálico basado en el ritual simbólico, El rey está desnudo, efectivamente, pero no importa porque se le atribuye este cuerpo segundo invisible que le da eficacia simbólica. ¿Qué pasa con la autoridad en la sociedad moderna, donde como anticipó Marx todo lo sólido se disuelva? En la sociedad liberal tenemos la autoridad invisible, manipulativa, de lo que Lacan Ilamaba el discurso universitario, es decir científico-tecnológico. El Otro no existe, el cuerpo del rey está desnudo pero hacemos como si estuviera vestido. Obedecemos por el conformismo de sujetos narcisistas y consumistas. La autoridad totalitaria se basa, como decía, en la identificación con el líder y con el grupo que representa. El rey puede estar desnudo, en el peor de los casos, pero es como si dentro de este cuerpo se mantuviera algo valioso que representa al Otro (la nación, el pueblo, la raza, el pueblo).Es la servidumbre voluntaria y el rechazo del goce del Otro.

Hay una diferenciar, de todas maneras, entre el totalitarismo nazi y el estalinista. El nazismo es un delirio paranoico, es levantar un Otro, que es el Partido como representante de la Raza, contra este Otro amenazador, que son los judíos. El goce del estalinismo es, por el contrario, un goce perverso, porque los comunistas son un instrumento para el goce del Otro, que es la Clase obrera portadora de un destino histórico emancipador. Al contrario que en la democracia, que considera que los antagonismos son internos, que quiere convertir el antagonismo en agonismo, en el totalitarismo el antagonismo es entre los que están dentro y los que están fuera, que hay que eliminar. Para los nazis hay que exterminar a todos los que entran en este Otro amenazador. Pero para los estalinistas cualquiera que no sea un instrumento adecuado del Partido es un traidor a eliminar. Esto hace que, paradójicamente, las posibles victimas estén mas definidas en el nazismo que en el estalinismo, en el que cualquiera puede ser la siguiente víctima, incluso el verdugo de hoy. De todas maneras para Žižek hay algo de verdad en el estalinismo, que es que es un resto de la Revolución rusa. Esto hace que a veces Žižek provoque a la izquierda liberal definiéndose como un estalinista dogmático. Mientras que en el nazismo no hay nada de verdad, es un puro simulacro. pero en todo caso es el goce del superyó más oscuro el que está en juego. El mal se fundamenta entonces en este goce del odio y del fanatismo.

Claro que, al final, como el mismo Žižek experimentó como ciudadano de un país comunista, el totalitarismo acaba en su propio simulacro y nadie se cree lo que se predica, con lo cual pasamos a un país de cínicos donde se cumple la ley por miedo. Entonces si podemos hablar de la banalidad del mal. 


\section{¿Qué hacer?}

Evidentemente después de la crítica al liberalismo y al totalitarismo la pregunta es que hacer. ¿Qué hacer para qué? Que hacer para la emancipación de todos y cada uno de nosotros, porque Žižek no renunciar a su ideal emancipatorio. Emanciparse quiere decir vivir según el propio deseo, no ceder en este punto, como plantea Lacan. Pero no desde lo privado sino desde lo público y para ello Žižek reivindica el comunismo como idea reguladora- El comunismo le permite enlazar con la economía política y desde ella criticar las propuesta democrático radicales de política pura, que van desde Alain Badiou hasta Jacques Rancière, pasando por Ernesto Laclau. No hay emancipación posible desde la política, hay que transformar la economía. Esto nos lleva a Lenin y a la afirmación de la lucha de clases. Porque es justamente la lucha de clases el anatagonismo real que niega el liberalismo, es lo reprimido que luego se manifiesta como racismo y nacionalismo. En este sentido Žižek citica todas las derivas que pretender diluir o eliminar la lucha de clases a favor de luchas culturales como el femenismo, el movimiento gay o el ecologismo. Hay que reinventar al izquierda. Hay que pensar sobre el estalinismo, como lo traumático de la izquierda que no se ha atrevido a abordar. Pero también hay que rechazar opciones como el troskismo, encasillado en unos tópicos que hoy no son un instrumento de lucha. Al socialliberalismo hay que aplicarle lo que ha dicho sobre el liberalismo y afirma que es la mejor opción política actual del capitalismo en cuanto a sus intereses globales, no en cuanto a las facciones en lucha del gran capital.

Hay finalmente un planteamiento de Žižek que me parece muy sugerente. Es el del encuentro de Marx con Kant. De Kant hay que recuperar el texto sobre la ilustración. No solo el atrévete a pensar También la defensa que hace lo público de lo privado. Lo privado es justamente la identidad particular, lo étnico o lo nacional. Esto es lo que hay que superar en nombre del universal concreto, que quiere decir ir hacia lo universal desde la singularidad de cada cual. Pero lo problemático es, para Žižek justamente lo que es lo universal. Por la tradición antihumanista de la que proviene se niega a aceptar el humanismo y los derechos humanos. Defenderá entonces un ir hacia lo universal a partir de colectivos universalizadores, que van desde las primeras comunidades cristianas (San Pablo contra el etnicismo judío) hasta el comunismo de Lenin. Aquí es donde me parece que resbala el filósofo esloveno. La salida me parece que es justamente ir desde lo singular hacia una ciudadanía, esta sociedad civil cosmopolita de la que habla Kant, que no es otro que el ideal republicano de la libertad, la igualdad y la fraternidad. 


\section{Bibliografía}

ROCA JUSMET, Luis (2008): "Slavoj Žižek. La filosofia com espai radical”, Els marges de la filosofía. Barcelona: La Busca.

ROCA JUSMET, Luis (2012): “Claude Lefort: Repensar la política”, Filosofías postmetafísicas, 20 años de filosofía francesa contemporánea. Barcelona: UOC.

ŽıžEK Slavoj (1998): Porque no saben lo que hacen. El goce como factor político. Buenos Aires: Paidós.

ŽıžeK Slavoj (1999): El acoso de las fantasias. México: XXI.

ŽıžEK Slavoj (2000): Mirando al sesgo: una introducción a Jacques Lacan a través de la cultura popular. Buenos Aires: Paidós.

ŽıžEK Slavoj (2000): El espinoso sujeto: el centro ausente de la ontología política. Buenos Aires: Paidós.

ŽıžEK Slavoj (2002): El frágil absoluto o porqué merece la pena luchar por el legado cristiano. Valencia: Ed. Pretextos.

žıžEK Slavoj (2002): ¿¿Quién dijo totalitarismo? Valencia: Ed. Pretextos.

ŽıžEK Slavoj (2004) A proposito de Lenin. Política y subjetividad en el capitalismo tardío. Buenos Aires: Ed. Atuel/Parusia.

ŽıžEK Slavoj (2004): Violencia en acto: Conferencias en Buenos Aires. Buenos Aires: Ed. Paidós.

ŽıžEK Slavoj (2004): Amor sin piedad: hacia una política de la verdad. Buenos Aires: Ed. Paidós.

ŽıžEK Slavoj (2006): Arriesgar lo imposible. Conversaciones con Glyn Daly. Madrid: Ed Trotta. 